\title{
Rubella Serosurvey Among Future Healthcare Workers
}

\author{
Andrea Trevisan*, Paola Mason, Annamaria Nicolli, Stefano Maso and Chiara Bertoncello \\ Department of Cardiac Thoracic Vascular Sciences and Public Health, University of Padova (Italy), Padova, Italy
}

Objective: Rubella is a very diffusive but relatively benign infectious disease unless contracted during pregnancy, when it causes congenital rubella syndrome. The aim of this research was to determine the prevalence and titer of antirubella antibodies in a population of future healthcare workers (students at the school of medicine).

Methods: The cohort consisted of 11,022 students who underwent antibody analysis after the presentation of a vaccine certificate.

Results: Vaccination compliance was very high, particularly in younger students (born after 1995), reaching almost 100\% (at least one dose). Unvaccinated students born before 1990 had high seropositivity (>95\%), but this percentage dropped to zero among

OPEN ACCESS

Edited by:

Caterina Ledda,

University of Catania, Italy

Reviewed by:

Georgios Merekoulias,

University of Patras, Greece

Luigi De Maria,

University of Bari Aldo Moro, Italy

*Correspondence:

Andrea Trevisan

andrea.trevisan@unipd.it

Specialty section:

This article was submitted to

Occupational Health and Safety,

a section of the journal

Frontiers in Public Health

Received: 14 July 2021

Accepted: 13 August 2021

Published: 13 September 2021

Citation:

Trevisan A, Mason P, Nicolli A, Maso S and Bertoncello C (2021) Rubella

Serosurvey Among Future Healthcare Workers.

Front. Public Health 9:741178. doi: 10.3389/fpubh.2021.741178 the youngest students. Variables affecting antibody titer included year of birth and sex. Considering only vaccinated students, a greater antibody response was observed if the vaccine was administered between 8 and 10 years of age. Female sex was associated with more significant $(p<0.0001)$ positivity and higher antibody titer after one and two doses. However, this difference appeared less consistent in relation to year of birth.

Conclusions: The studied population exhibited excellent vaccination compliance, high seropositivity, and high antibody titer. Vaccine and immune coverage were higher than what is deemed necessary to achieve herd immunity.

Keywords: rubella, rubella vaccine, rubella antibodies, medical students, healthcare workers

\section{INTRODUCTION}

Rubella is an acute viral infection caused by an RNA togavirus (genus Rubivirus). A high percentage of rubella infections in both children and adults are subclinical, but rubella during pregnancy is associated with potentially serious complications for the fetus due to congenital rubella syndrome (CRS).

Since 1999, the Italian Board of Health has encouraged the measles, mumps, and rubella (MMR) vaccine, and a mass vaccination campaign was launched (1), even though the single rubella vaccine has been available since 1972. The rubella vaccine was actively offered to adolescent women during primary or secondary school from 1972 to the cohort 1988-1989. Notwithstanding the high percentage of immunity (acquired via disease or vaccination), relatively low compliance with vaccination is why rubella has continued to circulate in Italy and CRS still occurs (2). Fortunately, however, between 2005 and February 2018, only 88 cases of CRS were registered in Italy, and only 173 cases of rubella disease during pregnancy were reported (3). 
In 2017, Italy approved the National Plan for Eradication of Measles and Congenital Rubella (4), according to the objectives of World Health Organization (WHO) 2012-2020 (5). Furthermore, according to the law established in 2017, the rubella vaccine (as MMR) is mandatory in Italy (6).

Moreover, the "National Vaccination Prevention Plan" 20172019 (4) recommends that healthcare workers (HCWs) be vaccinated against seven transmissible diseases, including rubella. Rubella immunity induced by vaccination appears to be persistent; therefore, routine booster immunizations do not seem to be necessary (7). However, a second immunization program should be considered to achieve high antibody-positivity rates and protect against primary vaccination failure. Several reports suggest that one dose can produce lifelong immunity (8) and that the vaccine induces a long-lasting antibody response of up to 21 years (9). The vaccination program carried out in Finland also eliminated CRS from that country (10).

The aim of this research was to evaluate the compliance with rubella vaccination, the percentage of seropositivity, and antibody titer according to the vaccination schedules (one or two doses) in a cohort of future HCWs recruited from a population of medical school students.

\section{METHODS}

\section{Population}

A cohort of 11,022 students enrolled at the School of Medicine of the University of Padua (Italy) were recruited (2004-2020) according to the following inclusion criteria: (1) born in Italy and therefore possessing uniform vaccination cards, (2) able to present a recent vaccination certificate issued by the Public Health Office, and (3) have a quantitative assay of antibodies against rubella.

The study involved 3,759 males (34.1\%) and 7,263 females (65.9\%) enrolled in medical and surgical degree courses $(4,922,44.7 \%)$, dentistry $(334,3.0 \%)$, and health professions (5,766, 52.3\%). Geographically, most students originated from Northern Italy (93.6\%), particularly the Veneto region (85.6\%). Data were collected during health surveillance in compliance with legislative decree 81/08 and European Community Directive 90/679.

\section{Antibody Measurement}

Antirubella IgG antibody titer was measured using the EIA Enzygnost method (Dade Behring, Marburg, Germany), and the results are reported as positive $(>10 \mathrm{IU} / \mathrm{mL})$, negative $(<4 \mathrm{IU} / \mathrm{mL})$, or equivocal $(4-10 \mathrm{IU} / \mathrm{mL})$. Antibody levels were examined in relation to history of disease, vaccination, or both. Equivocal results were statistically processed as negative according to Centers for Disease Control and Prevention (CDC) recommendations (11).

\section{Statistics}

The $2 \times 2$ chi-square $\left(\chi^{2}\right)$ test (Yates correction) was used to compare the differences in the prevalence of positive antibodies. Comparisons between means were made using the unpaired $t$-test (assuming unequal variances). The linear regression coefficient $r$ (Pearson's product-moment correlation coefficient) was calculated to correlate single independent variables with rubella antibody titer. Multiple linear regression analysis was employed to identify the variables affecting antibody level (dependent variable), such as (independent variables) sex, year of birth, and the number of vaccine doses received (none, one, or two). In all regression analyses (linear and multiple), the antibody titer data were $\log _{10}$-transformed due to the asymmetric distribution. Furthermore, 7 year-of-birth groups were established: before 1960, between 1961 and 1969, 1970 and 1979, 1980 and 1985, 1986 and 1990, 1991 and 1995, and after 1995. Other statistical analyses were descriptive. Significance is stated as $p<0.05$. Statsdirect version 2.7.7 (Statsdirect Ltd., Birkenhead, Merseyside, UK) was used for statistical analyses.

\section{RESULTS}

Compliance with rubella vaccination began to increase in subjects born in the decade 1970-1979, almost exclusively for women, who reached $\sim 50 \%$ vaccination coverage (one dose). In subsequent years, a progressive increase in vaccination

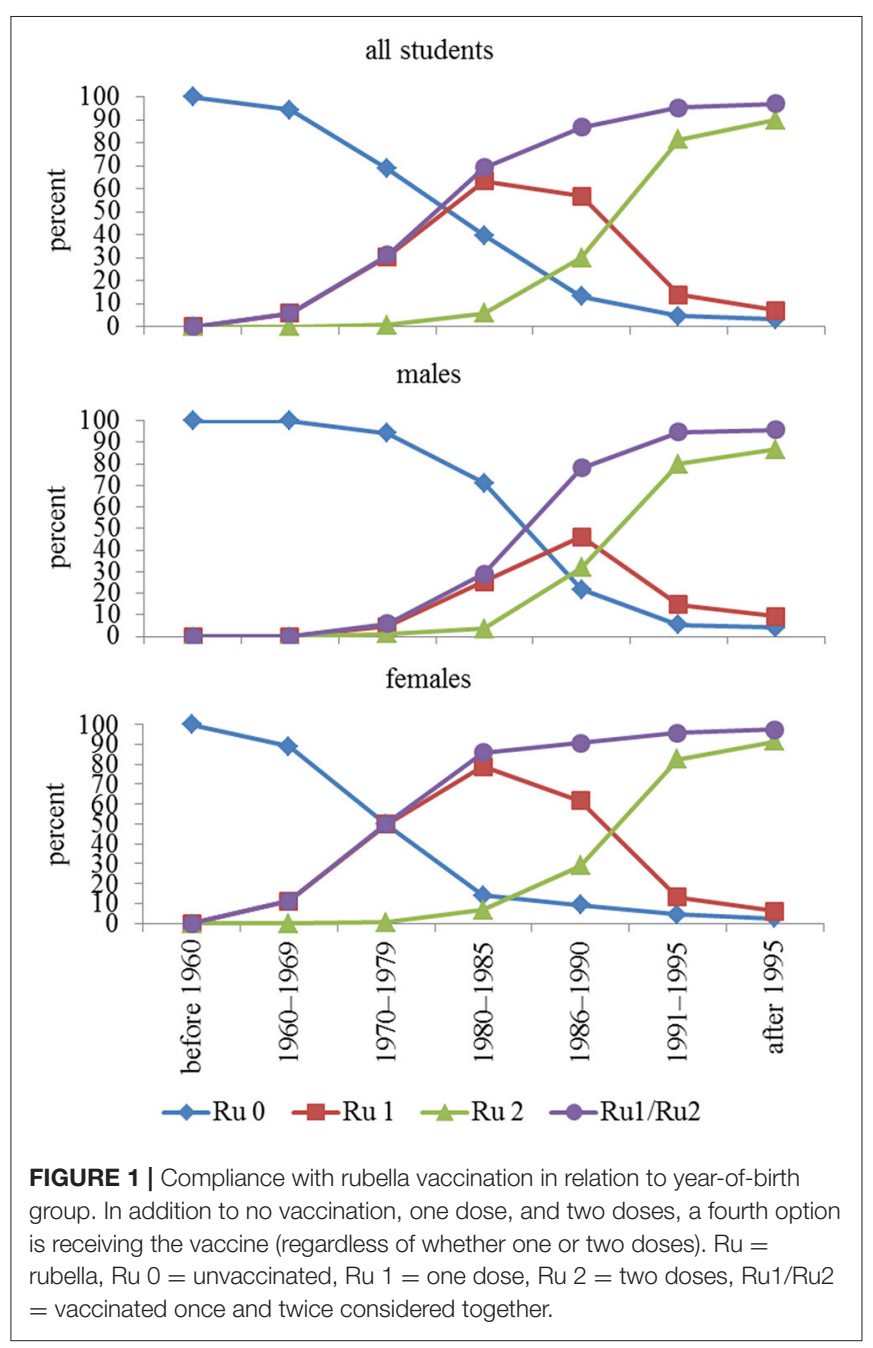


TABLE 1 | Seropositivity and antibody titer in unvaccinated students and students vaccinated with one or two doses.

\begin{tabular}{|c|c|c|c|c|c|c|c|}
\hline No vaccine & $N$ & Positives & $\%$ & $p$ & $\begin{array}{l}\text { Titer IU/mL } \\
\text { Mean } \pm \text { SD }\end{array}$ & $p$ & $\begin{array}{l}\text { Time* } \\
\text { Years }\end{array}$ \\
\hline All & 1,404 & 1,218 & 86.8 & & $129.8 \pm 106.1$ & & \\
\hline Males & 792 & 698 & 88.1 & & $136.7 \pm 109.8$ & & \\
\hline Females & 612 & 520 & 85.0 & n.s. & $120.8 \pm 100.5$ & 0.0048 & \\
\hline \multicolumn{8}{|l|}{ One dose } \\
\hline All & 3,236 & 3,157 & 97.6 & & $105.4 \pm 83.9$ & & $13.8 \pm 5.1$ \\
\hline Males & 776 & 735 & 94.7 & & $82.1 \pm 80.0$ & & $15.7 \pm 5.3$ \\
\hline Females & 2,460 & 2,422 & 98.5 & $<0.0001$ & $112.7 \pm 83.8$ & $<0.0001$ & $13.2 \pm 4.9$ \\
\hline \multicolumn{8}{|l|}{ Two doses } \\
\hline All & 6,382 & 6,192 & 97.0 & & $63.2 \pm 58.0$ & & $10.1 \pm 3.0$ \\
\hline Males & 2,191 & 2,101 & 95.9 & & $58.2 \pm 56.6$ & & $10.3 \pm 2.9$ \\
\hline Females & 4,191 & 4,091 & 97.6 & 0.0002 & $65.8 \pm 58.6$ & $<0.0001$ & $10.1 \pm 3.0$ \\
\hline
\end{tabular}

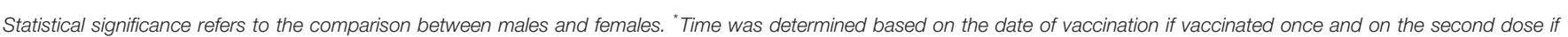
vaccinated twice.

compliance was observed in males, reaching a coverage (at least one dose) close to $100 \%$ (97\%), as shown in Figure 1. Overall, 9,618 students were vaccinated (87.3\%), of which 3,236 (29.4\%) had one dose and 6,382 (57.9\%) had two doses.

The vaccine, even after one dose, exhibited not only high coverage (97\%), but also high seropositivity (>90\%), even if the antibody titer, after both one and two doses, progressively declined in younger subjects.

Table 1 shows the differences in seropositivity and antibody titer between males and females; when considered collectively and subdivided according to the vaccination schedules, females were significantly more responsive than males with both one and two vaccine doses. It is also of interest that between those vaccinated, there was no statistically significant difference in the percentage of positives between those receiving one or two doses, but paradoxically, antibody titer was higher (1.67 times) in those vaccinated with one dose, even though the time between last vaccine dose and analysis was almost 4 years less in those vaccinated twice than in those vaccinated once.

However, by categorizing the students by year of birth and sex, even if a greater response from females was observed, it appeared less consistent and only in some year-of-birth groups (Table 2).

To better highlight this relationship, the two parameters (antibody titer and age at first dose) were plotted (Figure 2). A significant correlation was observed $(r=0.389, p<0.0001)$ with two particular age groups: between 1 and 2 years and that of $\sim 11$ years. The first probably consisted of subjects who afterward received a second dose of vaccine, whereas the second brings together both those who received only one dose during adolescence (particularly females) and those who received the second dose between the age of 8 and 11 years. The significant effect of the time between receiving the vaccine and the date of the analysis (data not shown) was significant $(p<0.0001)$ only from a statistical point of view due to the large number of samples, but it was not significant from an objective point of view $(r=-0.071)$.

Among unvaccinated students, a high rate of positivity for antibodies against rubella was observed in those born before 1990, although the number was dramatically reduced among females (due primarily to high compliance), and then seropositivity progressively declined to zero among younger students (Figure 3).

Multivariate analyses highlighted the effect of independent variables on antibody titer developed both after infection and after vaccination (Table 3). In panel A, all students were evaluated, including unvaccinated students: Year of birth, sex, and vaccination showed a significant effect on the antibody titer. In panel B, where the effect of independent variables was evaluated only in vaccinated students, the age at which the first dose of vaccine was administered is of particular interest. The number of vaccine doses administered did not affect the antibody titer.

Finally, a comparative analysis of seropositivity and antibody titer after the administration of the vaccine alone or in the MMR formulation was performed (Table 4). The effect of the vaccine alone (one dose) or the vaccine alone plus MMR (two doses) exhibited a more significant response in terms of seropositivity and antibody titer $(p<0.0001)$. It should be noted that the vaccine alone was used almost exclusively in females and before the year 2000. Only one student was vaccinated with two doses of rubella vaccine alone.

\section{DISCUSSION}

Rubella vaccination coverage appears to be optimal, especially for those born after 1985 (with at least one dose, >90\%), reaching $97.5 \%$ in those born after 1995 . Of interest is the fact that in those born before 1990, there is a significant discrepancy in vaccination compliance between males and females, with females much more compliant. This is likely related to two main factors: (1) the awareness that women of child-bearing age are at higher risk of CRS in the event of infection and (2) the active on-site supply of rubella vaccinations for teenage females during the last year of primary and first year of secondary school from 1972 to the 1988-1989 cohort. 
TABLE 2 | Characteristics of antibodies against rubella in terms of positivity percentage and antibody titer.

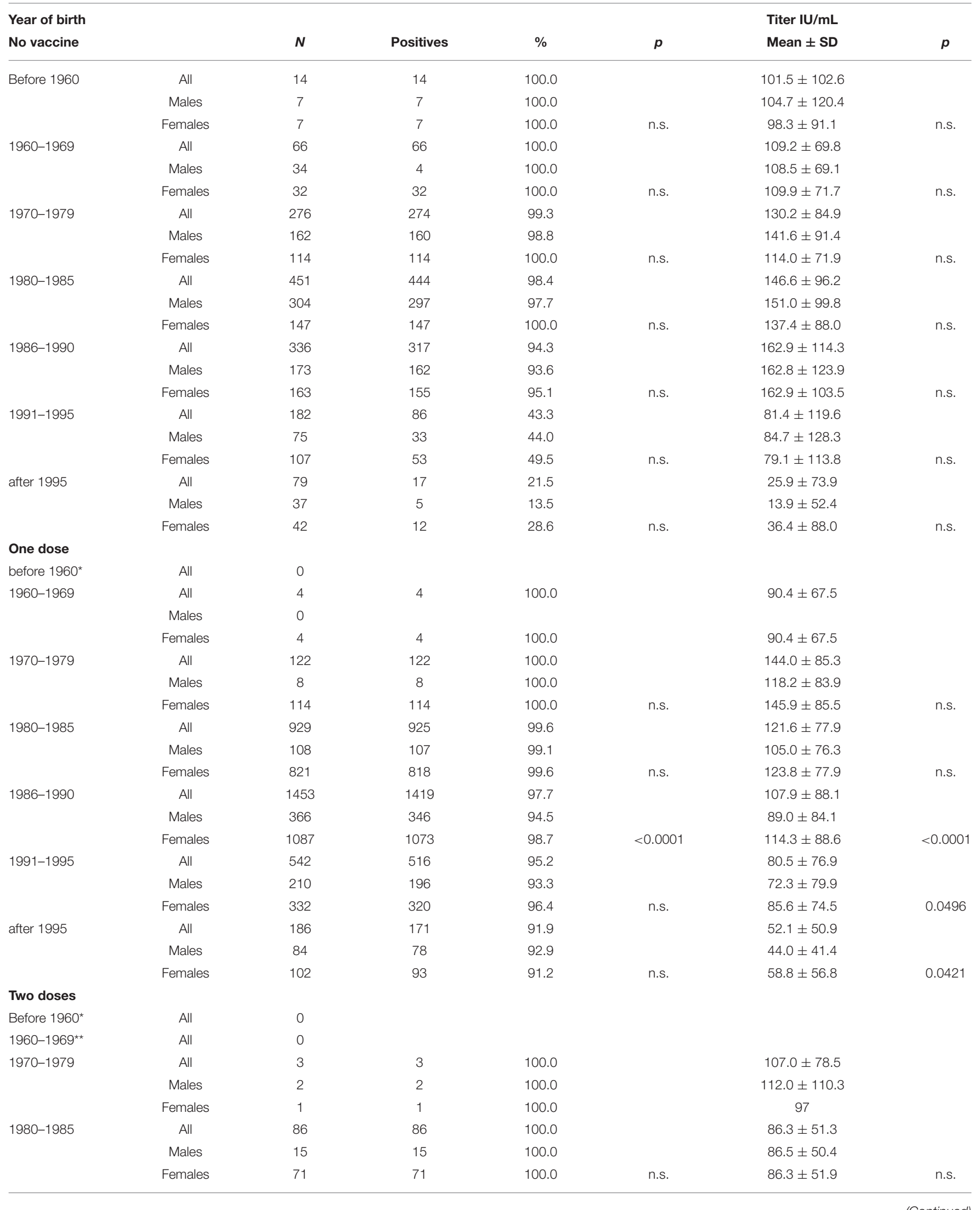


TABLE 2 | Continued

\begin{tabular}{|c|c|c|c|c|c|c|c|}
\hline \multirow[t]{2}{*}{ Year of birth } & & \multirow[b]{2}{*}{$N$} & \multirow[b]{2}{*}{ Positives } & \multirow[b]{2}{*}{$\%$} & \multirow[b]{2}{*}{$p$} & \multicolumn{2}{|l|}{ Titer IU/mL } \\
\hline & & & & & & Mean \pm SD & $p$ \\
\hline \multirow[t]{3}{*}{ 1986-1990 } & All & 765 & 754 & 98.6 & & $71.9 \pm 61.3$ & \\
\hline & Males & 252 & 249 & 98.8 & & $69.3 \pm 59.3$ & \\
\hline & Females & 513 & 505 & 98.4 & n.s. & $73.2 \pm 62.2$ & n.s. \\
\hline \multirow[t]{3}{*}{ 1991-1995 } & All & 3,182 & 3,136 & 98.6 & & $69.4 \pm 61.5$ & \\
\hline & Males & 1,130 & 1,101 & 97.4 & & $63.3 \pm 59.3$ & \\
\hline & Females & 2,052 & 2,035 & 99.2 & 0.0002 & $72.8 \pm 62.5$ & $<0.0001$ \\
\hline \multirow[t]{3}{*}{ After 1995} & All & 2,346 & 2,213 & 94.3 & & $51.0 \pm 49.5$ & \\
\hline & Males & 792 & 734 & 92.7 & & $46.7 \pm 49.5$ & \\
\hline & females & 1,554 & 1,479 & 95.2 & 0.0174 & $53.1 \pm 49.4$ & 0.0031 \\
\hline
\end{tabular}

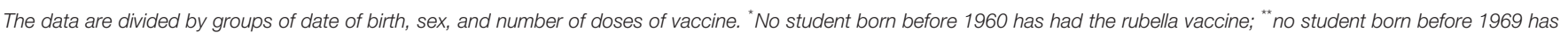
had two doses of the vaccine. Statistical significance refers to the comparison between males and females.

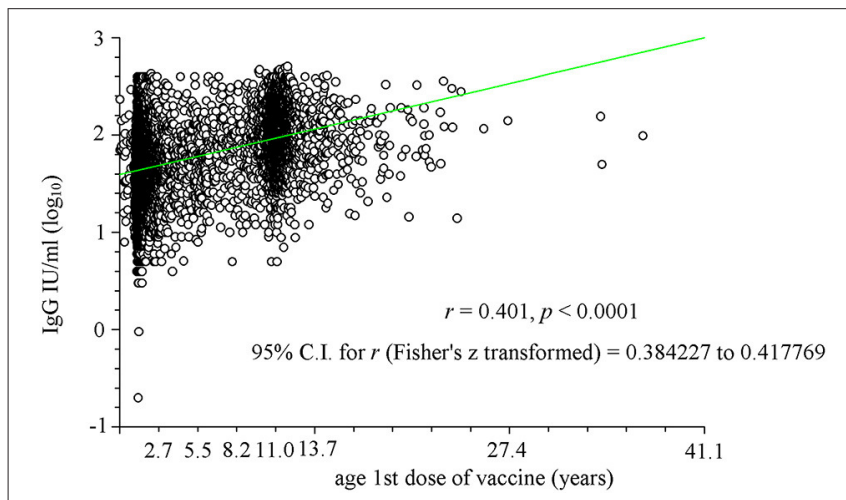

FIGURE 2 | Linear regression analysis of the relationship between age at which the first vaccine dose was administered (in years) and logarithm of antibody titer (IgG). Two particular age groups have been identified: between 1 and 2 years and that of $\sim 11$ years. The first age group consisted of subjects who afterwards received a second dose of vaccine, whereas the second brings together both those who received only one dose during adolescence (particularly females) and those who received the second dose between the age of 8 and 11 years.

Of further interest is evidence that seropositivity was high (>95\%) in those born before 1990, even if not vaccinated. For those born in subsequent years, seropositivity rapidly declined to $<20 \%$ and then to zero. This means a significant decrease in circulation of the wild virus and therefore a lack of natural boosters, which is probably the cause of the progressive reduction in antibody titer after vaccination in the youngest. On the other hand, the immune response to a single dose of vaccine is optimal, such that it alone achieves and exceeds herd immunity, which for rubella has been calculated at between 85 and $87 \%$ (12). It is therefore evident that between natural immunity and immunity acquired with the vaccine, the population of future HCWs will have an immunization rate close to $100 \%$. On the other hand, recent research in a cohort of female HCWs demonstrated that $\sim 10 \%$ had non-protective antibodies, suggesting a third dose of the vaccine would be needed in these cases (13).

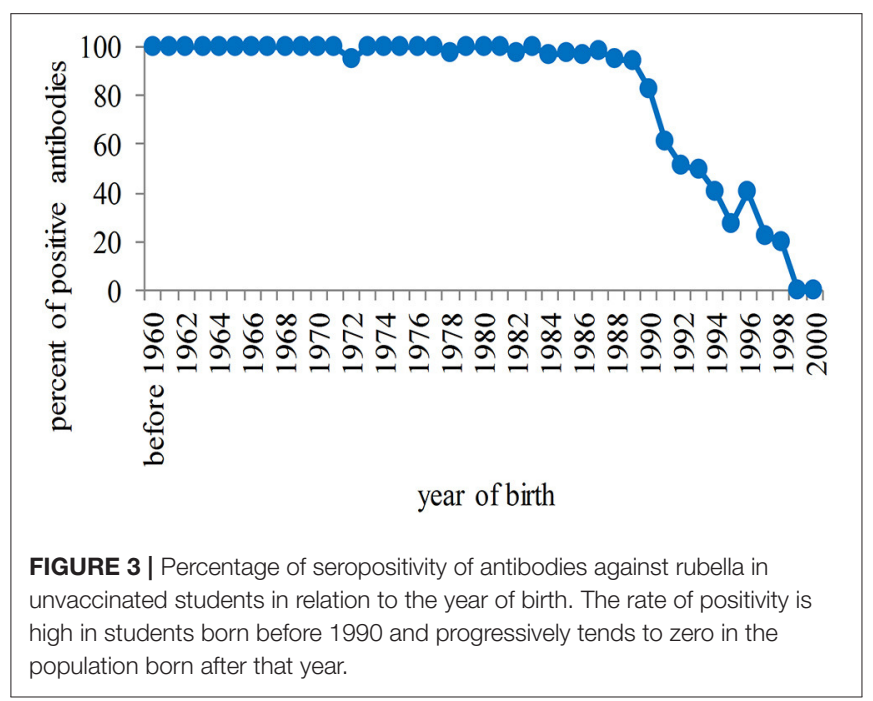

TABLE 3 | Panel A: Multiple linear regression analysis for all students, unvaccinated and vaccinated (once or twice); Panel B: The analysis was performed only for vaccinated subjects (once or twice).

\begin{tabular}{lcccc}
\hline Panel A & $\mathbf{b}$ & $\boldsymbol{r}$ & $\mathbf{t}$ & $\boldsymbol{p}$ \\
\hline Intercept & 54.471946 & & 34.669043 & $<0.0001$ \\
Year of birth & $-\mathbf{0 . 0 2 6 5 2 3}$ & $-\mathbf{0 . 3 0 3 8 5 3}$ & $-\mathbf{3 3 . 4 7 7 3 3 2}$ & $<\mathbf{0 . 0 0 0 1}$ \\
Sex & $\mathbf{0 . 0 7 5 3 5 6}$ & $\mathbf{0 . 0 9 0 5 1}$ & $\mathbf{9 . 5 3 3 4 3 2}$ & $<\mathbf{0 . 0 0 0 1}$ \\
Vaccination & $-\mathbf{0 . 0 2 0 8 4 2}$ & $\mathbf{0 . 0 2 8 6 4 8}$ & $\mathbf{3 . 0 0 8 3 0 7}$ & $\mathbf{0 . 0 0 2 6}$ \\
Panel B & & & & \\
Intercept & 2.099115 & & 50.369121 & $<0.0001$ \\
Year of birth & $-\mathbf{0 . 0 7 4 0 9 5}$ & $-\mathbf{0 . 1 6 0 4 9 4}$ & $-\mathbf{1 5 . 9 4 1 6 6 6}$ & $<\mathbf{0 . 0 0 0 1}$ \\
Sex & $\mathbf{0 . 0 6 6 6}$ & $\mathbf{0 . 0 8 9 4 1 6}$ & $\mathbf{8 . 8 0 1 6 4 3}$ & $<\mathbf{0 . 0 0 0 1}$ \\
Vaccination & -0.015588 & -0.011065 & -1.084844 & 0.278 \\
Age 1st dose & $\mathbf{0 . 0 0 0 0 5 7}$ & $\mathbf{0 . 1 5 0 0 2}$ & $\mathbf{1 4 . 8 7 6 4 5 6}$ & $<\mathbf{0 . 0 0 0 1}$ \\
Time & $-\mathbf{0 . 0 0 0 0 2 8}$ & $-\mathbf{0 . 0 9 1 6 6 7}$ & $-\mathbf{9 . 0 2 5 1 1 3}$ & $<\mathbf{0 . 0 0 0 1}$ \\
\hline
\end{tabular}

Time is the interval between the last dose of vaccine and the measurement of antibodies (logarithmic transformation). Significant results are in bold. 
TABLE 4 | Comparative analysis of seropositivity and antibody titer after administration of the vaccine alone or in the MMR formulation.

\begin{tabular}{|c|c|c|c|c|c|c|c|}
\hline One dose & $N$ & Positives & $\%$ & $p$ & $\begin{array}{l}\text { Titer IU/mL } \\
\text { mean } \pm S D\end{array}$ & $p$ & $\begin{array}{l}\text { Time* }^{*} \\
\text { Years }\end{array}$ \\
\hline Rubella alone & 1,049 & 1,046 & 99.7 & & $129.4 \pm 81.3$ & & $12.7 \pm 4.5$ \\
\hline MMR & 2,187 & 2,111 & 93.9 & $<0.0001$ & $93.9 \pm 82.7$ & $<0.0001$ & $14.3 \pm 5.2$ \\
\hline \multicolumn{8}{|l|}{ Two doses } \\
\hline $\begin{array}{l}\text { Rubella alone } \\
+ \text { MMR }\end{array}$ & 110 & 110 & 100.0 & & $101.8 \pm 72.4$ & & $8.4 \pm 3.8$ \\
\hline $\mathrm{MMR}+\mathrm{MMR}$ & 6,272 & 6,082 & 97.0 & n.s. & $62.5 \pm 57.5$ & $<0.0001$ & $10.2 \pm 2.9$ \\
\hline
\end{tabular}

Statistical significance refers to the comparison between rubella vaccine alone (or alone plus MMR) and MMR formulation. "Time was determined based on the vaccination date if vaccinated once and on the second dose if vaccinated twice.

The high seropositivity in a very large cohort confirms that the rubella vaccine is particularly effective (14-18); the efficacy of one dose is $>95 \%$, and if high coverage is achieved, only one dose is required to achieve rubella elimination $(19,20)$. Indeed, two doses of the vaccine do not increase seropositivity and surprisingly result in a lower antibody titer. An adequate explanation is not at this moment available, except considering two factors: (1) One dose was administered at an older age (around 8 years) than the first dose, when the vaccine was administered twice ( $\sim 2$ years of age), and (2) the greater efficacy of the vaccine alone, widely used in the past, especially in females, in the single-dose vaccination schedule compared to the combined MMR vaccine, as already demonstrated for that vaccine against measles (21). Furthermore, our results clearly demonstrate that the antibody titer is significantly greater when the vaccine is administered in adolescence compared with that in childhood. Because infants lose maternally acquired immunity within 9 months of birth (22), vaccination is important to prevent rubella above all in women of child-bearing age (23).

Our results show that sex influences the antibody response, significantly higher in females, in terms of both seropositivity and antibody titer, with one or two doses. However, this difference is less consistent in relation to the years of birth, and males have a longer time interval between vaccine and serological analysis, especially if vaccinated with a single dose. The adaptive immunity in females is greater (24), and better vaccination response has been demonstrated for some vaccine types (25-27), but is not consistent for rubella (28) or for chickenpox (29).

The present research has the following weakness: Only the antibody titer was determined and not neutralizing antibodies. However, in such a large cohort, that analysis was economically impractical.

\section{CONCLUSIONS}

In conclusion, the results of this study show that both the vaccination and the immune coverage of future HCWs against rubella are optimal, well above that required for herd immunity. The coverage also includes the male sex, which in the past was not considered necessary, as rubella is a generally benign disease, with the understanding that the eradication of rubella, and therefore of congenital rubella, did not pass only from females and that males play a role, if not vaccinated, in keeping the wild virus in circulation. Based on data provided by the Istituto Superiore di Sanità, Italy is approaching the eradication of congenital rubella, and the complete immunization of HCWs is a good start. The modest difference in the sex-related immune response to the vaccine does not appear substantial from our point of view.

\section{DATA AVAILABILITY STATEMENT}

The raw data supporting the conclusions of this article will be made available by the authors, without undue reservation.

\section{ETHICS STATEMENT}

Ethical review and approval was not required for the study on human participants in accordance with the local legislation and institutional requirements. The patients/participants provided their written informed consent to participate in this study.

\section{INSTITUTIONAL REVIEW BOARD STATEMENT}

This was an observational study in which we analyzed data obtained from a mandatory health surveillance of workers exposed to biological risks regulated by Italian legislative decree $81 / 2008$; consequently, evaluation by an ethics committee was not necessary.

\section{AUTHOR CONTRIBUTIONS}

$\mathrm{AT}, \mathrm{CB}$, and $\mathrm{PM}$ involved in conceptualization, writing the review, and editing. $\mathrm{CB}$ involved in methodology. AT and $\mathrm{PM}$ involved in validation. AT involved in formal analysis, data curation, and supervision. AT, AN, and SM involved in investigation. AT and $\mathrm{CB}$ involved in writing the original draft preparation. All authors have read and agreed to the published version of the manuscript.

\section{REFERENCES}

1. Ministero della Salute. Circolare n. 12. Controllo ed eliminazione di morbillo, parotite e rosolia per mezzo della vaccinazione (Circular 12. Control and Elimination of Measles, Mumps

and Rubella by Means of Vaccination). Rome: Ministry of Health (1999).

2. Ciofi degli Atti M, Filia A, Revello MG, Buffolano W, Salmaso S. Rubella control in Italy. Euro Surveill. (2004) 9:19-21. doi: 10.2807/esm.09.04.00462-en 
3. Istituto Superiore di Sanità. Rosolia Congenita e in Gravidanza (Congenital Rubella and During Pregnancy). Rapporto semestrale n. 8, Marzo (2018). Available online at: https://www.epicentro.iss.it/rosolia/bollettino (accessed Feb 25, 2021).

4. Piano Nazionale Prevenzione Vaccinale 2017-2019 (National Vaccination Prevention Plan 2017-2019). Rome: Ministero della Salute (2017).

5. World Health Organization. Global Measles and Rubella Strategic Plan 2012-2020. WHO Library Cataloguing-in-Publication Data. Printed in Switzerland. World Health Organization (2012). Available online at: https://www.who.int/publications/i/item/9789241503396 (accessed July 9, 2021).

6. Decreto legge n. 73. Disposizioni Urgenti in Tema di Prevenzione Vaccinale (Law Decree N. 73. Urgent Provisions on Vaccine Prevention). Rome, Italy (2017). Gazzetta Ufficiale N. 130, June 7, 2017.

7. Balfour $\mathrm{HH}$ Jr. Rubella immunization now. Am J Dis Child. (1979) 133:1231-33. doi: 10.1001/archpedi.1979.021301200 23001

8. Davidkin I, Peltola H, Leinikki P, Valle M. Duration of rubella immunity induced by two-dose Measles, Mumps and Rubella (MMR) vaccination. A 15-year follow-up in Finland. Vaccine. (2000) 18:3106-12. doi: 10.1016/S0264-410X(00)00139-0

9. O'Shea S, Woodward S, Best JM, Banatvala JE, Holzel H, Dudgeon JA. Rubella vaccination: persistence of antibodies for 10-21 years. Lancet. (1988) 332:909. doi: 10.1016/S0140-6736(88)92512-3

10. Davidkin I, Peltola H, Leinikki, P. Epidemiology of rubella in Finland. Euro Surveill. (2004) 9:13-14. doi: 10.2807/esm.09.04.00459-en

11. Centers for Disease Control and Prevention. Prevention of varicella. Update recommendations of the Advisory Committee on Immunization Practices (ACIP). Mobid Mortal Weekly Rep. (1999) 48:1-5.

12. Anderson RM, May RM. Immunisation and herd immunity. Lancet. (1990) 335:641-45. doi: 10.1016/0140-6736(90)90420-A

13. Coppeta L, Ferrari C, Iannuzzi I, D’Alessandro I, Balbi O, Pietroiusti A, et al. rubella immunity among italian female healthcare workers: a serological study. Int J Environ Res Public Health. (2020) 17:7992. doi: 10.3390/ijerph17217992

14. Trevisan A, Morandin M, Frasson C, Paruzzolo P, Davanzo E, Di Marco L, et al. Prevalence of childhood exanthematic disease antibodies in paramedical students: need of vaccination. Vaccine. (2006) 24:17176. doi: 10.1016/j.vaccine.2005.07.062

15. Trevisan A, Frasson C, Morandin M, Beggio M, Bruno A, Davanzo E, et al. Immunity against infectious diseases: predictive value of self-reported history of vaccination and disease. Infect Control Hosp Epidemiol. (2007) 28:564-69. doi: 10.1086/516657

16. Crooke SN, Haralambieva IH, Grill DE, Ovsyannikova IG, Kennedy RB, Poland GA. Seroprevalence and durability of rubella virus antibodies in a highly immunized population. Vaccine. (2019) 37:3876-82. doi: 10.1016/j.vaccine.2019.05.049

17. Karadeniz A, Akduman Alaşehir E. Seroepidemiology of hepatitis viruses, measles, mumps, rubella and varicella among healthcare workers and students: should we screen before vaccination? J Infect Public Health. (2020) 13:480-84. doi: 10.1016/j.jiph.2020.01.309

18. Trevisan A, Bertoncello C, Artuso E, Frasson C, Lago L, De Nuzzo D, et al. Will we have a cohort of healthcare workers fully vaccinated against measles, mumps, and rubella? Vaccines. (2020) 8:104. doi: 10.3390/vaccines8010104
19. Rubella vaccines: WHO position paper. Wkly Epidemiol Rec. (2011) 86:301-16. Available online at: https://apps.who.int/iris/handle/ 10665/241786 (accessed July 9, 2021).

20. Rubella vaccines: WHO position paper - july 2020. Wkly Epidemiol Rec. (2020) 95:306-24. Available online at: https://apps.who.int/iris/handle/10665/ 332952 (accessed July 9, 2021).

21. Trevisan A, Mason P, Nicolli A, Maso S, Scarpa B, Moretto A, et al. Vaccination and immunity towards measles: a serosurvey in future healthcare workers. Vaccines. (2021) 9:377. doi: 10.3390/vaccines9040377

22. Dimech W, Mulders MN. A 16-year review of seroprevalence studies on measles and rubella. Vaccine. (2016) 34:411018. doi: 10.1016/j.vaccine.2016.06.002

23. Gallone MS, Gallone MF, Larocca AMV, Germinario C, Tafuri S. Lack of immunity against rubella among italian young adults. BMC Infect Dis. (2017) 17:199. doi: 10.1186/s12879-017-2724-y

24. Klein SL, Jedlicka A, Pekosz A. The Xs and Y of immune responses to viral vaccines. Lancet Infect Dis. (2010) 10:33849. doi: 10.1016/S1473-3099(10)70049-9

25. Cook IF. Sexual dimorphism of humoral immunity with human vaccines. Vaccine. (2008) 26:3551-55. doi: 10.1016/j.vaccine.2008.04.054

26. Kennedy RB, Ovsyannikova IG, Pankratz VS, Vierkant RA, Jacobson RM, Ryan MA, et al. Gender effects on humoral immune responses to smallpox vaccine. Vaccine. (2009) 27:3319-23. doi: 10.1016/j.vaccine.2009.01.086

27. Trevisan A, Frasson C, De Nuzzo D, Nicolli A, Scapellato ML. Significance of anti-HB levels below $10 \mathrm{IU} / \mathrm{L}$ after vaccination against hepatitis B in infancy or adolescence: an update in relation to sex. Hum Vaccin Immunother. (2020) 16:460-64. doi: 10.1080/21645515.2019.1656483

28. Hoes J, Knol, MJ, Mollema L, Buisman A, de Melker HE, et al. Comparison of antibody response between boys and girls after infant and childhood vaccinations in the Netherlands. Vaccine. (2019) 37:450410. doi: 10.1016/j.vaccine.2019.06.055

29. Trevisan A, Nicolli A, De Nuzzo D, Lago L, Artuso E, Maso S. Varicella seroepidemiology and immunization in a cohort of future healthcare workers in the pre-vaccination era. Int J Infect Dis. (2020) 96:22832. doi: $10.1016 /$ j.ijid.2020.04.082

Conflict of Interest: The authors declare that the research was conducted in the absence of any commercial or financial relationships that could be construed as a potential conflict of interest.

Publisher's Note: All claims expressed in this article are solely those of the authors and do not necessarily represent those of their affiliated organizations, or those of the publisher, the editors and the reviewers. Any product that may be evaluated in this article, or claim that may be made by its manufacturer, is not guaranteed or endorsed by the publisher.

Copyright (c) 2021 Trevisan, Mason, Nicolli, Maso and Bertoncello. This is an openaccess article distributed under the terms of the Creative Commons Attribution License (CC BY). The use, distribution or reproduction in other forums is permitted, provided the original author(s) and the copyright owner(s) are credited and that the original publication in this journal is cited, in accordance with accepted academic practice. No use, distribution or reproduction is permitted which does not comply with these terms. 